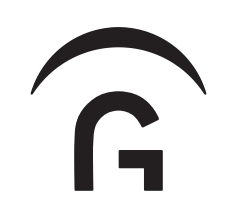




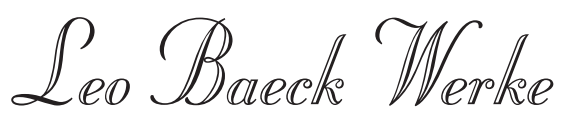

Herausgegeben von

Albert H. Friedlander (London) $\dagger$

Bertold Klappert (Wuppertal), Werner Licharz (Frankfurt a.M.),

Michael A. Meyer (Cincinnati/Ohio), im Auftrag des Leo Baeck Instituts, New York

Die Herausgeber danken Marianne C. Dreyfus, James N. Dreyfus und Richard B. Dreyfus für die Erlaubnis,

Leo Baecks Werke wieder im Druck erscheinen zu lassen.

Band $I$

Das Wesen des Judentums

Band 2

Dieses Volk

Band 3

Wege im Judentum

Band 4

Aus Drei Jahrtausenden.

Das Evangelium als Urkunde

der jüdischen Glaubensgeschichte

Band 5

Schriften aus der Nachkriegszeit

Band 6

Briefe, Reden, Persönliches

\section{Gütersloher Verlagshaus}




\title{
Band 3
}

\section{Wege im Judentum \\ Aufsätze und Reden}

\author{
Herausgegeben \\ von Werner Licharz
}


Bibliografische Information der Deutschen Nationalbibliothek Die Deutsche Nationalbibliothek verzeichnet diese Publikation in der Deutschen Nationalbibliografie; detaillierte bibliografische Daten sind im Internet über https://portal.dnb.de abrufbar.

Copyright @ 1997 Gütersloher Verlagshaus, Gütersloh, in der Verlagsgruppe Random House GmbH, Neumarkter Str. 28, 81673 München

Der Inhalt dieses E-Books ist urheberrechtlich geschützt und enthält technische Sicherungsmaßnahmen gegen unbefugte Nutzung.

Die Entfernung dieser Sicherung sowie die Nutzung durch unbefugte

Verarbeitung, Vervielfältigung, Verbreitung oder öffentliche

Zugänglichmachung, insbesondere in elektronischer Form, ist untersagt und kann straf- und zivilrechtliche Sanktionen nach sich ziehen.

Sollte diese Publikation Links auf Webseiten Dritter enthalten, so übernehmen wir für deren Inhalte keine Haftung, da wir uns diese nicht zu eigen machen, sondern lediglich auf deren Stand zum Zeitpunkt der Erstveröffentlichung verweisen.

Umschlagfoto: Leo Baeck Institut, New York Satz: Weserdruckerei Rolf Oesselmann GmbH, Stolzenau

ISBN 978-3-641-24,844-4 www.gtvh.de 